\title{
Analysis on the Instrumental and Experiential Attitudes towards Bribery among Youths from Different Types of Primary and Secondary Schools in Malaysia
}

Lim Mengzhen, Wan Munira Wan Jaafar, Azlina Mohd Khir, Hanina H. Hamsan

To Link this Article: http://dx.doi.org/10.6007/IJARBSS/v11-i11/11660

DOI:10.6007/IJARBSS/v11-i11/11660

Received: 08 September 2021, Revised: 02 October 2021, Accepted: 27 October 2021

Published Online: 13 November 2021

In-Text Citation: (Mengzhen et al., 2021)

To Cite this Article: Mengzhen, L., Jaafar, W. M. W., Khir, A. M., \& Hamsan, H. H. (2021). Analysis on the Instrumental and Experiential Attitudes towards Bribery among Youths from Different Types of Primary and Secondary Schools in Malaysia. International Journal of Academic Research in Business and Social Sciences, 11(11), 1767-1784.

Copyright: (c) 2021 The Author(s)

Published by Human Resource Management Academic Research Society (www.hrmars.com)

This article is published under the Creative Commons Attribution (CC BY 4.0) license. Anyone may reproduce, distribute, translate and create derivative works of this article (for both commercial and non0-commercial purposes), subject to full attribution to the original publication and authors. The full terms of this license may be seen

at: http://creativecommons.org/licences/by/4.0/legalcode

Vol. 11, No. 11, 2021, Pg. 1767 - 1784

Full Terms \& Conditions of access and use can be found at http://hrmars.com/index.php/pages/detail/publication-ethics 


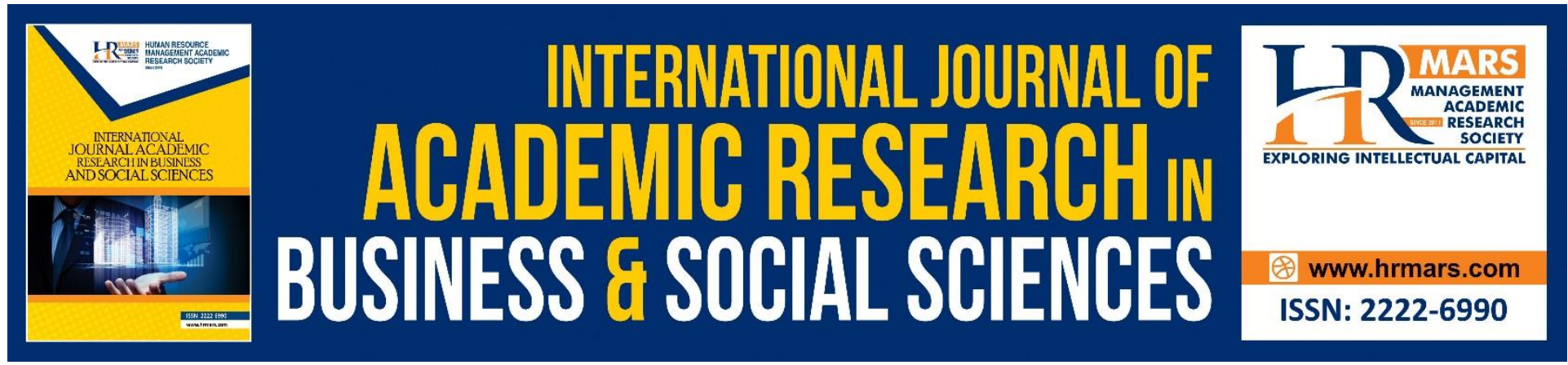

\title{
Analysis on the Instrumental and Experiential Attitudes towards Bribery among Youths from Different Types of Primary and Secondary Schools in Malaysia
}

\author{
Lim Mengzhen \\ Department of Psychology, School of Medical and Life Sciences, Sunway University \\ 47500 Petaling Jaya, Selangor.
}

\author{
Wan Munira Wan Jaafar, Azlina Mohd Khir, Hanina H. Hamsan \\ Department of Social And Development Sciences, Faculty of Human Ecology, \\ Universiti Putra Malaysia, 43400 Serdang, Selangor. \\ Email: wanmunira@upm.edu.my
}

\begin{abstract}
Attitudes explain a wide range of behaviours including bribery. As the education environment plays a crucial role in communicating messages about what behaviour is acceptable, the ways we structure our school system could potentially influence how attitudes are shaped. In Malaysia, students attended different types of primary and secondary school (e.g. national and vernacular). Thus, this study aimed to explore the instrumental and experiential attitudes towards bribery of students attended four different types of primary and secondary schools. There were 198 Malaysian youths with an age range of 18 to $29(M=20.43)$ participated in this study. Instrumental and experiential attitudes towards bribery scales were used to measure both variables. Kruskal-Wallis test was used and the results indicated that there were no significant differences found between instrumental attitudes or experiential attitudes towards bribery among youths from four different types of schools selected in this study. However, some respondents claim that offering a small amount of money is more acceptable than offering a large amount of money. The implied that the acceptability of a dishonest act depends on its seriousness.
\end{abstract}

Keywords: Education, Vernacular School, Attitudes, Bribery, Corruption

Introduction

It is virtually impossible not to think of corruption as one of the principal reasons why Malaysia has failed to achieve its Vision 2020 and to be recognized as a developed nation. From 20132017, the country has lost about RM235 billion (about USD 56 billion) due to corruption. This is about four per cent of the country's gross domestic product (GDP) every year (Bradbury \& Yuvaraj, 2019). Money that could be used for development was spent in the form of 
corruption. Therefore, understanding the root cause of corrupt behaviour is crucial in order to curb this dishonest behaviour.

In Malaysia, among all the national scandals that occurred, the three significant corruption cases are: (a) National Feedlot Centre (NFC)'s 250 millions of Malaysian Ringgit [RM] (about USD 61 million), a government funds that should be used to grow the local beef market ended up with NFC buying luxury condos (Grudgings, 2012); (b) Malaysian Anti-Corruption Agency (MACC) seized RM114 million (about USD 28 million) from the director and deputy of Sabah Water Department; and (c) 1MDB scandal, the mother of all scandals, costs the government billions of ringgit (Benen, 2017). Jeff Sessions, the U.S. attorney-general, used the term "kleptocracy at its worst" to describe this scandal (Sipalan, 2017).

Corruption research in Malaysia has focused on disciplines such as business (Azmi, 2016), economics (Hashim, 2017), and finance (Kapeli \& Mohamed, 2019). Even though most research used the term corruption, they are referring to one specific type of corruption, which is bribery. Bribery is the most common type of corruption (Nicholas \& Robertson, 2017). Bribery is defined as the abuse or misuse of power or trust in a quid pro quo exchange (Nicholas \& Robertson, 2017, p.4). Bribery occurs when two parties are involved either in receiving, asking or giving any gratification thus induces a favour with corrupt intent (Alatas, 1991). An example of bribery is when a police officer asks for a small amount of money to disregard unlawful behaviour.

Generally, bribery could happen in three ways. The first one is asking, e.g., police officers ask for bribes. The second one is receiving, e.g., police officers receive money. The last one is offering or paying bribes, e.g., a driver pays money to the police officer. Asking or receiving brides are usually linked to those who hold authority or power such as politicians, police or local council authority whereas offering brides usually involves the general population. Bribery is also the most common form of bribery that the general public is involved in. Society has often overlooked that individuals who give or pay bribes are also part of the system.

Bribing behaviour can be explained using the cost-benefit analysis (Becker, 1968). According to this theory, people's behaviour to bribe or not to bribe results from three considerations: (1) how much would they gain from paying the bribe, (2) the probability that they will be caught by the authority and (3) the heaviness of the punishment if they were caught. Efforts to combat this behaviour is often based on this theory. For example, the government department specifies no gift policy from the customer and increases the punishment sentence for the bribery-related offence. But, with only this effort, bribe behaviour cannot be controlled effectively. This is no surprise as Mazar et al (2008) have refuted this theory as the core to understand dishonest behaviour.

Psychology offers a deeper understanding of this dishonest behaviour. Zaloznaya (2014) suggested that non-Western societies could use Social Psychology theory to understand corrupt behaviour. The psychology field suggests two main factors that influence human behaviour which are "attitudes" (Fishbein \& Ajzen, 2010) and "education". Thus, this study aims to explore the preliminary finding of the descriptive analysis on attitude towards bribery of students who graduated from four different types of schools in Malaysia by asking the following two questions: (1) How do graduates from four types of schools (SK to SMK, SJK to 
SMK, SJK to SMJK and SJK to SMP) score on the attitudes towards bribery, and (2) are there any significant differences between graduates who attended different types of schools and attitudes towards bribery?. SK is a public primary school, SJK is a Chinese vernacular primary school, SMK is a public secondary school, SMJK is a Chinese vernacular secondary school and SMP is a private Chinese high school. Past literature about attitudes and education will be reviewed.

\section{Attitudes}

The theory of reasoned action approach posits that attitudes towards the behaviour could have a great influence on the behaviour (Fishbein \& Ajzen, 2010). Attitude refers to the positive or negative evaluations of the behaviour, and it is determined from the individual's beliefs about the advantages/disadvantages of performing the behaviour (White et al., 2015). A valid attitude measure should include both instrumental and experiential attitudes (as cited in Wan et al., 2017). Instrumental attitude is an individual's evaluation of the behavioural outcome (e.g., bribe is unacceptable) whereas experiential attitude is an individual's affective feelings toward behaviour (e.g., bribery is an unpleasant experience). Previous studies have reported that both instrumental and experiential attitudes are important factors influencing intention and behaviour. This is because negative instrumental attitudes (e.g., bribing police is not acceptable) may be subdued by the positive feelings towards a given behaviour. On the other hand, negative experiential attitudes (bribing police is not a pleasant experience) might also be suppressed by the positive function projected by the behaviour. Thus, measuring both instrumental and experiential attitudes separately could lead to a more accurate representation of attitudes.

Instrumental attitudes could be measured by asking participants adjectives such as good to bad (Fishbein \& Ajzen, 2010). These attitudes have been found to be predictors of intention and behaviour in education settings and behavioural studies that were conducted among undergraduate and middle age groups. For example, in the education setting, Prenger and Schildkamp (2018) suggested that instrumental attitude is an important predictor of behaviour. Teachers who believe that data use can lead to improvement act in the same way when prodigy classroom instruction to students. In a previous road-crossing violation study in Dalian, China that was carried out with undergraduate students, it is found that instrumental attitude has a significant relationship with people's violating behaviour (Zhou et al., 2016). In a health risk study with participants of mean age of 39, instrumental attitude was also found to be a significant positive predictor of intention to engage in risky behaviour (Conner et al., 2017).

On the other hand, experiential attitudes were commonly found in attitudes-related studies (Wan et al., 2017) and were used to measure health-related attitudes (e.g., Dong \& Branscum, 2019; Head \& lannarino, 2017). This could be measured by asking participants adjectives such as unpleasant to pleasant (Fishbein \& Ajzen, 2010). Past study with undergraduate students found that experiential attitudes were positively associated with one's intentions to intervene to stop a sexual assault (Reynolds-Tylus et al., 2019). van Wasshenova et al (2018) conducted a study with older adults found a positive correlation between experiential attitudes and weight fitness. Considering the available research reviewed above, in the context of this study, if students believe that bribery is acceptable, they are more likely to bribe 
(instrumental attitudes). Moreover, if students believe that bribing is a pleasant experience (experiential attitudes), they are more likely to bribe.

Bribery often happens to adults as they have more capacity to carry out the act. For example, in order to bribe a police officer to disregard their unlawful behaviour, they must first obtain a license to drive and have money to offer a bribe. Nevertheless, it is very important to understand and shape one's attitudes towards bribery during school time. Newcomb's (1943) longitudinal study highlighted that attitudes shaped during college time would remain intact for a long period of time. He conducted the survey with 500 female students in their 20 s about their political attitudes, the second survey when they were 40s and the third survey was when they were in their 60s. The research found that liberal attitudes remain intact. This suggests the strong relationship between education and attitudes that must be explored. In fact, school is one of the most important institutions in our society that not only educates but also shapes students' beliefs and behaviour (Kowalski, 2007). Thus, it is important to understand the current school environment vis-à-vis bribery. Notwithstanding, schools in Malaysia uphold the same national curriculum, the environments that carry this curriculum can greatly differ. For example, a student could attend a national primary school (SK) and another same age student could choose to receive the same education in a Chinese vernacular school (SJK).

\section{Education}

School is the best place to shape a proper attitude towards bribery. The Stanford prison experiment has shown how important an environment is as it would directly influence one's behaviour (Haney et al., 1996). In 2020, The Ministry of Education Malaysia (MOE) received an allocation of RM 64.1 billion (about USD 15.7 billion) or $21.6 \%$ of the total country expenditure (Ministry of Flnance, 2019). The education system in Malaysia is carried out based on the Education Act 1996 and it is governed by the Ministry of Education (Malaysian Government, 1996). This is a system partially inherited from the United Kingdom. Malaysian government provides eleven years of national educational services which could be divided into six years of primary school and five years of secondary school. It is compulsory to attend six years of primary school. This education system resulted from the independence agreement in 1957.

Generally, schools in Malaysia segregate students based on race and mother tongue language. Despite growing up in a very different school environment, every school has their own version of success stories. However, there are limited scientific studies available to understand how students differed when they graduated and understanding these differences could help us in restructuring the environment so that we can eliminate bribery.

Primary School. There are two main types of primary school in Malaysia, National Primary School or "Sekolah Kebangsaan" (SK) and National-type Chinese Primary School or "Sekolah Jenis Kebangsaan Cina" (SJK). Table 1 presents the summary of primary school.

SK uses the Malay language as the medium of instruction whose students are learning subjects such as history in the Malay language (Gill et al., 2013). This school is mainly attended by Malay children even though all have equal rights to attend this school. There are approximately 2.1 million students attending this type of school (Lim, 2018). On the other hand, SJK uses the Mandarin Language as the medium for instruction as students are learning 
the core subjects in Mandarin despite Malay and English languages being compulsory subjects. This school is mainly attended by Malaysian Chinese even though all Malaysian have equal rights to attend this school. Approximately five hundred thousand students are attending SJK school. Both schools are funded by the government of Malaysia.

Table 1: Summary of Primary Schools Types (“Senarai Sekolah," 2020)

\begin{tabular}{lcc}
\hline & SK & SJK \\
\hline Medium of instruction & Malay & Mandarin \\
Owner & Ministry of Education & Ministry of Education \\
Funding & Public & Public \\
Numbers of schools & 5876 & 1299 \\
Number of students & $2,125,612$ & 511,950 \\
Number of teachers & 188,360 & 36,581 \\
\hline
\end{tabular}

Secondary School. Majority of Malaysians went through one of these three types of secondary school: National Secondary School or "Sekolah Menengah Kebangsaan" (SMK), National-type Chinese secondary schools or "Sekolah Menengah Jenis Kebangsaan" (SMJK), and Chinese Private Secondary Schools or "Sekolah Menengah Persendirian Cina" (SMP). Table 2 presents the summary of secondary school.

SMK uses the Malay language as the medium of instruction and students are learning subjects such as history in the Malay language. This type of school is fully funded by the government. For SMJK, it is similar to SMK whereby it is using the Malay language as the medium of instruction for a variety of subjects. The main difference is that this type of school is usually attended by Malaysian-Chinese. This type of school receives full or partial financial assistance from the government. On the other hand, SMP is privately owned by Dong Zhong and does not receive government fundings. This school does not use the national language as a medium of instruction. The syllabus and textbooks are prepared by Dong Zong and students will sit for the Unified Examination Certificate (UEC).

Table 2: Summary of Secondary School Types ("Senarai Sekolah," 2020)

\begin{tabular}{lccc}
\hline & SMK & SMJK & SMP \\
\hline Medium of instruction & Malay & Malay & Mandarin \\
Owner & Ministry of Education & Ministry of Education & Dong Zong \\
Funding & Public & Public & Private \\
Numbers of schools & 1809 & 78 & 60 \\
Number of students & $1,613,760$ & 108,000 & 85,304 \\
\hline
\end{tabular}


Note: Based on Lim (2017). Dong Zong is The United Chinese School Committees Association of Malaysia.

In Malaysia, there are three major environmental differences across different types of schools. The first difference is race and cultural background. Malaysians would voluntarily segregate their children based on race and cultural background. In school, students would interact with those from similar backgrounds. Experiments that aim to measure the magnitude of dishonesty across cultures were conducted in Israel, United States, China, Italy, Turkey, Canada, and England where no cultural differences were found (Ariely, 2012). Lab experiments do not reflect the actual social or cultural environment. Cultural context influences dishonest behaviour and transitions them into and out of the moral domain. For example, unlike most of the American universities, photocopying a textbook is surely unethical and will be viewed in a very negative manner. In other cultures, getting caught could be viewed as negative instead of the act of photocopying itself.

The second difference is about funding for school. According to the Malaysia Education Blueprint 2013-2025, the Ministry of Education (MOE) allocates teachers for both types of schools and pays their salaries. The MOE fully funds national schools expenses such as utilities, renovation and construction (Lim, 2017), teachers training (Gill \& Berezina, 2020), but funding for national-type schools might be limited. One of the notable conflicts regarding funding occurred in 2008 where the Power Authority shut off service to SMJK Chung Cheng in Kota Bharu because the school failed to pay the power bill leaving their students to study without light and fan (Sin Chew Daily, 2008). Research has shown that inequality treatment could lead to dishonesty (Birkelunda \& Cherry, 2020). In their experiment, it was learnt that when advantages only benefit one group, the disadvantaged group would be more dishonest.

The third difference is the language usage in the school environment. It has been established the decisions and behaviour of people are affected by the language used for communication (Keysar et al., 2012). It was found that there is also an observed difference when individuals use their mother tongue as compared to a second language during the decision-making process (Costa et al., 2014). According to research by Ivaz et al. (2016), this could be because people tend to use second languages in professional settings where there is lower emotional significance. Chen and Bond (2010) found that when conversing with the study participants, they were perceived as more extroverted, open, and assertive when conversing in English rather than in Chinese.

Environments do impose a certain influence on students. In a research done to test the morality of Chinese and American students, it was found that Chinese students are more comfortable with academic dishonesty as compared to American students (Rawwas et al., 2004). In a similar study, it was found that the Chinese were intolerant towards organizational bribery compared to individual bribery. In contrast, Americans were more intolerant towards individual bribery (Liu et al., 2017). This study did note that the possibility of internal attributions for the bribe payers as a mediating variable in the relationship (Liu et al., 2017). In addition to this study, Tian (2008) found that bribery was related to moral realism among Chinese business managers. 


\section{Methods}

\section{Ethical considerations}

This research was approved by the chair of University Research Ethics Committee.

\section{Study design}

This is a quantitative and cross-sectional study using an online survey method to recruit respondents. All respondents were recruited using a convenience sampling method.

\section{Respondents}

Respondents in this study were Malaysian youths $(\mathrm{N}=198)$ with an age range from 18 to 29 and a mean age of 20.43 years old. There are 95 (48.00\%) male and 103 (52.00\%) female. Among these respondents, 181 (91.4\%) are currently enrolled as college or university students. In terms of ethnicity, 149 (75.3\%) reported to be Malaysian Chinese. Respondents were categorized into four groups based on their educational background. Please refer to Table 3.

Table 3: Four types of school respondents attended $(N=198)$

\begin{tabular}{cccc}
\hline Code & Primary School & High School & $n(\%)$ \\
\hline SK $>$ SMK & SK & SMK & $67(33.8 \%)$ \\
SJK $>$ SMK & SJK & SMK & $68(34.3 \%)$ \\
SJK $>$ SMJK & SJK & SMJK & $32(16.2 \%)$ \\
SJK $>$ SMP & SJK & SMP & $31(15.7 \%)$ \\
\hline
\end{tabular}

Note: SK $=$ National Primary School, SJK = National-type Chinese Primary School, SMK= National Secondary School, SMJK= National-type Chinese secondary schools, SMP $=$ Chinese Private Secondary Schools

\section{Measurement}

\section{Education}

Three self-report questions about school attended were asked. Respondents were asked to self-report the types of schools they attended for primary, secondary and college or university. Based on the data collected, four groups were formed. Please refer to Table 3.

\section{Attitudes towards bribery}

Instrumental attitudes towards bribery and experiential attitudes towards bribery were measured using the concept of Situational Judgement Tests (SJT). Five bribery scenarios from the Corruption Acceptance Survey (Truex, 2010) were modified to incorporate in this study. All characters in the original scenarios were changed to either traffic police, government officers or immigration officers. Those scenarios are as follows:

1. [Large Money] In Malaysia, a person offers a traffic police a large amount of money to overlook their unlawful behaviour.

2. [Small Money]In Malaysia, a person offers a traffic police a small amount of money to overlook their unlawful behaviour. 
3. [Small Gift] In Malaysia, a person offers a traffic police a small gift to overlook their unlawful behaviour.

4. [Illicit giver] In Malaysia, a person gives a government employee a small gift in order to obtain a passport without proper documentation

5. [Deserved Giver] In Malaysia, because of a delay, a person gives an immigration officer a small gift in order to make sure that his passport gets processed

Scenarios one to three are about the means of bribes, and scenarios four and five are about rationalisation. For each scenario, two questions to measure instrumental attitudes and experiential attitudes were presented using 7-points Likert scale. Scores recorded for each variable using the five scenarios were summed up. Please refer to Table 4.

Table 4: Survey Question, Meaning of High Score and Reliability for All Variables

\begin{tabular}{|c|c|c|c|c|}
\hline Variables & Survey question & Meaning of high score & Reliability & $\begin{array}{c}\text { Total } \\
\text { questions }\end{array}$ \\
\hline $\begin{array}{l}\text { Instrumental } \\
\text { attitudes } \\
\text { towards } \\
\text { bribery }\end{array}$ & $\begin{array}{l}\text { The person's } \\
\text { action is } \\
\text { acceptable. }\end{array}$ & $\begin{array}{l}\text { Stronger beliefs about giving } \\
\text { bribes that are determined } \\
\text { by the beliefs of the } \\
\text { outcomes of giving bribes. }\end{array}$ & .87 & 5 \\
\hline $\begin{array}{l}\text { Experiential } \\
\text { attitudes } \\
\text { towards } \\
\text { bribery }\end{array}$ & $\begin{array}{l}\text { If I am the person } \\
\text { as described in the } \\
\text { scenario, it is a } \\
\text { pleasant } \\
\text { experience to act } \\
\text { in the same } \\
\text { manner. }\end{array}$ & $\begin{array}{l}\text { Higher emotional response } \\
\text { of the individual to the idea } \\
\text { of giving a bribe. }\end{array}$ & .89 & 5 \\
\hline
\end{tabular}

\section{Procedure}

The survey was conducted online via Google forms. Respondents were required to complete a consent form before taking part in the survey. After the respondents consented to participate, demographic questions were collected. There were five bribery scenarios presented to the respondents, and after every scenario, instrumental attitudes and experiential attitudes were measured. SPSS software was used to analyse the collected data from respondents.

\section{Results}

\section{Research question one}

Research question one aims to answer how graduates from four types of schools (SK to SMK, SJK to SMK, SJK to SMJK and SJK to SMP) score on the attitudes towards bribery. Table 5 and 6 presents the descriptive statistics to understand how graduates from four types of schools (SK to SMK, SJK to SMK, SJK to SMJK and SJK to SMP) score on the attitudes towards bribery. Table 5 presents the central tendency of instrumental attitudes and experiential attitudes according to types of schools. Table 6 shows the central tendency of instrumental attitudes and experiential attitudes for every single scenario. 
Table 5: Variable analysis: Median, mean and standard deviations for instrumental attitudes and experiential attitudes according to school types

\begin{tabular}{lccc}
\hline \multicolumn{1}{c}{ Types of schools } & Median & Mean & Std. Deviation \\
\hline $\begin{array}{l}\text { Instrumental attitudes towards bribery } \\
\text { SK }>\text { SMK }\end{array}$ & 5.00 & 8.93 & 4.97 \\
SJK $>$ SMK & 5.00 & 9.43 & 5.28 \\
SJK $>$ SMJK & 5.00 & 9.97 & 6.57 \\
SJK $>$ SMP & 5.00 & 11.97 & 7.46 \\
Total & 5.00 & 9.74 & 5.84
\end{tabular}

\section{Experiential attitudes towards bribery}

$\begin{array}{lccc}\text { SK }>\text { SMK } & 6.00 & 8.43 & 4.63 \\ \text { SJK>SMK } & 7.00 & 9.93 & 6.75 \\ \text { SJK>SMJK } & 7.00 & 9.38 & 5.84 \\ \text { SJK>SMP } & 11.00 & 12.10 & 7.13 \\ \text { Total } & 7.00 & 9.67 & 6.10\end{array}$

Note: Possible minimum score is 5 and maximum score is $35 . \mathrm{SK}=$ National Primary School, SJK = National-type Chinese Primary School, SMK= National Secondary School, SMJK= National-type Chinese secondary schools, SMP = Chinese Private Secondary Schools 
There are eight unique trends observed from the data presented in Table 5 and 6.

Table 6 : Scenario Analysis: The median, means and standard deviations for instrumental attitudes and experiential attitudes according to each scenario

\begin{tabular}{|c|c|c|c|c|c|c|c|c|c|c|c|c|c|c|c|}
\hline & \multicolumn{3}{|c|}{$\begin{array}{c}\text { Scenario } 1 \\
\text { Large Money }\end{array}$} & \multicolumn{3}{|c|}{$\begin{array}{c}\text { Scenario } 2 \\
\text { Small Money }\end{array}$} & \multicolumn{3}{|c|}{$\begin{array}{l}\text { Scenario } 3 \\
\text { Small Gift }\end{array}$} & \multicolumn{3}{|c|}{$\begin{array}{l}\text { Scenario } 4 \\
\text { Illicit giver }\end{array}$} & \multicolumn{3}{|c|}{$\begin{array}{c}\text { Scenario } 5 \\
\text { Deserved Giver }\end{array}$} \\
\hline & Med & M & SD & Med & M & SD & Med & M & SD & Med & M & SD & Med & M & SD \\
\hline \multicolumn{16}{|c|}{ Instrumental attitudes towards bribery } \\
\hline SK $>$ SMK & 1.00 & 1.67 & 1.33 & 1.00 & 1.96 & 1.46 & 1.00 & 1.94 & 1.49 & 1.00 & 1.43 & 0.96 & 1.00 & 1.93 & 1.39 \\
\hline SJK $>$ SMK & 1.00 & 1.93 & 1.40 & 1.00 & 2.15 & 1.55 & 1.00 & 2.03 & 1.48 & 1.00 & 1.44 & 0.92 & 1.00 & 1.88 & 1.41 \\
\hline SJK>SMJK & 1.00 & 2.00 & 1.44 & 2.00 & 2.22 & 1.50 & 1.50 & 2.19 & 1.67 & 1.00 & 1.53 & 0.98 & 1.00 & 2.03 & 1.66 \\
\hline SJK $>S M P$ & 2.00 & 2.48 & 1.82 & 2.00 & 2.65 & 1.74 & 2.00 & 2.35 & 1.54 & 1.00 & 1.71 & 1.30 & 2.00 & 2.77 & 2.23 \\
\hline Overall & 1.00 & 1.94 & 1.47 & 1.50 & 2.17 & 1.55 & 1.00 & 2.08 & 1.52 & 1.00 & 1.49 & 1.01 & 1.00 & 2.06 & 1.61 \\
\hline \multicolumn{16}{|c|}{ Experiential attitudes towards bribery } \\
\hline SK: & 1.0 & 7 & 1.11 & 1.00 & 1.81 & 1.23 & 1.00 & 1.76 & 1.30 & 1.00 & 1.43 & 0.97 & 1.00 & 1.76 & 1.28 \\
\hline SJK>SMK & 1.00 & 1.90 & 1.46 & 1.00 & 2.19 & 1.66 & 1.00 & 2.07 & 1.61 & 1.00 & 1.66 & 1.33 & 1.00 & 2.10 & 1.84 \\
\hline SJK $>$ SMJK & 1.00 & 1.91 & 1.40 & 1.00 & 1.94 & 1.34 & 1.50 & 1.97 & 1.33 & 1.00 & 1.47 & 0.98 & 1.00 & 2.09 & 1.77 \\
\hline SJK $>$ SMP & 2.00 & 2.55 & 1.79 & 2.00 & 2.90 & 1.87 & 2.00 & 2.23 & 1.52 & 1.00 & 2.00 & 1.63 & 2.00 & 2.42 & 2.00 \\
\hline Overall & 1.00 & 1.92 & 1.42 & 1.00 & 2.13 & 1.55 & 1.00 & 1.97 & 1.45 & 1.00 & 1.61 & 1.23 & 1.00 & 2.04 & 1.6 \\
\hline
\end{tabular}

Note: Possible minimum score is 1 and maximum score is 7. Med = Median, $\mathrm{M}=$ Mean, $\mathrm{SD}=$ Standard deviation, SK = National Primary School, SJK = National-type Chinese Primary School, SMK= National Secondary School, SMJK= National-type Chinese secondary schools, SMP = Chinese Private Secondary Schools

First: Overall, as presented in Table 5 and 6, the low scores for median and mean are relatively stable across the four types of schools in both variable and scenario analysis. For example, in Table 5, for instrumental attitudes and experiential attitudes, the range for median was 5 to 11 and the mean range from 8.93 to 12.10 . For scenario analysis, the median ranges from 1 to 2 and the mean range from 1.43 to 2.90 .

Second: For instrumental attitudes, both variable and scenario analysis show a consistent pattern of how students from different types of schools score. For example, in Scenario One, students from $S K>S M K$ have the strongest belief that bribery is the least acceptable $(M=$ 1.67), follow by SJK $>$ SMK $(M=1.93)$, SJK $>$ SMJK $(M=2.00)$ and SJK $>S M P(M=2.48)$. This sequence was consistent across the variable instrumental attitudes and five scenarios.

Third: Variable and scenario analysis of experiential attitude found a slightly different trend. The similarity was that across scenarios, students from SK>SMK have the weakest belief that bribing is a pleasant experience and students from SJK $>$ SMP have the strongest belief that bribing is a pleasant experience. The opposite trend identified was that, in the variable analysis, the mean score indicated that students from SJK $>$ SMJK $(M=9.38)$ have the weaker belief as compared to students from SJK>SMK (M = 9.93). In Scenario Two, Three and Four, 
students from SJK >SMK scored higher than SJK >SMJK.

Fourth: It has also been noted that, for all scenarios across four types of schools, students from SJK>SMP scored above the overall mean for instrumental attitudes and experiential attitudes. For example, in Table 5, the mean score for instrumental attitudes is $M=9.74$ while students from SJK >SMP's M $=11.97$.

Fifth: The mean score for Scenario Two was higher than Scenario One for all schools types. For example, refer to Table 6, for instrumental attitudes, students from SK>SMK has a mean score of 1.97 for Scenario Two and $M=1.67$ for Scenario One. This revealed that offering traffic police a small amount of money is more acceptable than large amounts of money.

Sixth: When comparing Scenario Two and Three, the trends show that small money is still more acceptable than small gifts. The exception was with the score for instrumental experiential attitudes, students from SJK $>$ SMJK thinks that bribes using small gifts are more pleasant as compared to small money.

Seven: Comparing Scenario One and Three for instrumental attitudes and experiential attitudes, offering small gifts are more acceptable than large money, and it was a more pleasant experience. An exception was found with students from SJK $>$ SMP who scored the opposite.

Eight: In Scenario Four and Five, for both instrumental attitudes and experiential attitudes, students from all types of schools think that bribing because of a delay (deserved giver) is more acceptable than illicit givers.

\section{Research Question Two}

Research question two examines the differences between graduates who attended different types of schools and attitudes towards bribery. To answer if there are any significant differences between graduates who attended different types of schools and attitudes towards bribery based on attitudes variables and each scenario, two separate analyses were carried out as presented in Table 7 and Table 8. Levene's test for homogeneity of variance found that the data met the homogeneity of variance assumption. However, KolmogorovSmirnov tests found that the data was not normally distributed. Since the data do not meet the assumptions of a one-way between-subjects ANOVA, the Kruskal-Wallis test was used.

Table 7 displays the result of the Kruskal-Wallis test that explore the differences between graduates who attended different types of schools and attitudes variables. There were no significant differences found between the four types of schools on the instrumental attitudes and experiential attitudes. 
Table 7: Kruskal-Wallis test between instrumental attitudes and experiential attitudes and types of schools attended

\begin{tabular}{lccc}
\hline & $H$ & $d f$ & $p$ \\
\hline Instrumental attitudes towards bribery & 3.67 & 3 & .30 \\
Experiential attitudes towards bribery & 6.25 & 3 & .10 \\
\hline
\end{tabular}

To identify if there are any significant differences between students who attended different types of schools based on each scenario, Kruskal-Wallis test was also used. For Scenario One, significant differences were found for instrumental attitudes, $H(3)=8.06, p<$ .05 and experiential attitudes, $\mathrm{H}(3)=8.49, \mathrm{p}<.05$. Post-hoc analysis using Mann-Whitney Utests with Bonferroni corrections was conducted to examine the differences between types of schools. For instrumental attitudes, it was found that SK $>$ SMK was significantly different to SJK $>$ SMP $, p<.05, r=.28$, post hoc power $=.99$; Whereas for experiential attitudes, it was found that SK>SMK was significantly different to the SJK>SMP, $p<.05, r=.29$, post hoc power $=.99$.

Table 8: Kruskal-Wallis test between types of school and scenarios

\begin{tabular}{ccccc}
\hline Scenario 1 & Scenario 2 & Scenario 3 & Scenario 4 & Scenario 5 \\
Large Money & Small Money & Small Gift & Illicit giver & Deserved giver \\
\hline
\end{tabular}

Instrumental attitudes towards bribery

$\begin{array}{llllll}H & 8.06 & 5.21 & 3.33 & 2.13 & 4.13 \\ d f & 3.00 & 3.00 & 3.00 & 3.00 & 3.00 \\ p & 0.05^{*} & 0.16 & 0.34 & 0.55 & 0.25\end{array}$

Experiential attitudes towards bribery

\begin{tabular}{cccccc}
$H$ & 8.49 & 9.62 & 4.25 & 6.82 & 2.66 \\
$d f$ & 3.00 & 3.00 & 3.00 & 3.00 & 3.00 \\
$p$ & $0.04^{*}$ & $0.02^{*}$ & 0.24 & 0.08 & 0.45 \\
\hline
\end{tabular}

$* p<.05$

For Scenario Two, significant differences between the four types of schools were found for experiential attitudes towards bribery, $\mathrm{H}(3)=9.62, \mathrm{p}<.05$. The differences between types of schools were examined using post-hoc Mann-Whitney $U$ tests with Bonferroni corrections and found that the SK>SMK was significantly different to the SJK $>S M P, p<.05, r=.31$, post hoc power $=0.99$. Nevertheless, for Scenario Three, Four and Five, there were no significant differences found between the types of schools attended.

\section{Discussion}

Many Malaysians have expressed their opinions regarding corruption and educational issues that occurred in the country, but there is very limited scientific knowledge that might be relevant to the types of schools attended and bribery. This study focused on describing how do graduates from four types of schools (SK to SMK, SJK to SMK, SJK to SMJK and SJK to SMP) 
score on the attitudes towards bribery scale and if there are any significant differences between graduates who attended different types of schools in their attitudes towards bribery. Two types of attitudes towards bribery were explored namely instrumental and experiential attitudes.

This study revealed three important contributions to the pool of knowledge about schools and bribery attitudes in Malaysia. Firstly, we examine if there is any significant difference in instrumental and experiential attitudes towards bribery among youths who attended four different types of schools. Despite no significant differences was found, the descriptive result of the survey revealed interesting results. Some respondents indicated that offering a small amount of money is more acceptable than offering a large amount of money. The respondents also believed that bribery is fairly acceptable and they feel fairly pleasant to bribe. This result is not very unexpected as it is somehow consistent with research done by the Malaysian Integrity Institute in 2017. The research found that one in three university students are blind to corruption (Yusoff, 2017). These results seem to be consistent with the theory of self-concept maintenance (Mazar et al., 2008). According to this theory, people who behave dishonestly will still be able to see themself as good people. The possible reason why our respondents indicate bribery is fairly acceptable is because they want to benefit from bribery, but at the same time, they do not want to affect their good self-image. Thus, implying bribery is fairly acceptable is able to benefit them as well as not affecting their good selfimage. Future studies should focus on in-depth analysis on why people believe that bribery is something fairly acceptable and what they meant by daily acceptable.

Secondly, when comparing between schools, consistent trends were found where respondents graduated from SK>SMK school consistently rank the lowest for both attitudes measures in bribery and respondents from SJK $>$ SMP ranked the highest. Respondents from SJK $>$ SMK and SJK $>$ SMK ranked in between. One of the possible explanations would be students who attended SMP are constantly experiencing cognitive dissonance. On one hand, students believe that their school is the best as shown through areas such as academic results and worldwide recognition ("Top universities," 2015), but on another hand, their graduation certificate (UEC) is not recognised for further study within any local public university. Furthermore, instead of arguing about the quality UEC, the former Prime Minister argued that the recognition of UEC needs to consider the feelings of Malays (Malaysiakini, 2019). Thus, students from SMP may develop an unfair perception. Perceived unfairness would then increase dishonesty behaviour (Leib et al., 2019). However, more studies are needed to explore in detail the environmental factor in these schools.

On the other hand, students from different types of schools might develop group identity based on in-groups "us" versus out-groups "you" (as cited in Ciccarelli \& White, 2017). For example, a student from SMK school will see students from SMP school as an outgroup and vice versa. In cheating experiments involving in-group versus out-group members, the involvement of out-group members in the study reduces cheating (Gino et al., 2009). Seeing bribery as something to be done by out-group members could potentially decrease the level of positiveness towards bribery. If students from SMK see bribery as something done by the out-groups, this would explain the result why they are the most negative when it comes to instrumental and experiential attitudes. 
Thirdly, different means to bribe were also measured using different scenarios. For example, in Scenario One, the means to bribe is using a large amount of money. Out of five scenarios, Scenario One (large money) and Two (small money) are the only scenarios that found some significant differences. For Scenario One, respondents from SJK>SMP think that offering traffic police officers a large amount of money to disregard their unlawful behaviour is more acceptable and a higher pleasant experience as compared to students from SK $>S M K$. For Scenario Two on offering a small amount of money, students from SJK $>$ SMP think that it is a more pleasant experience than students from $S K>S M K$ but there are no differences regarding acceptance between schools. Based on the descriptive statistic, respondents regardless of school types, believe that bribing traffic police with a small amount of money is more acceptable and pleasant than large amounts of money. Besides that, offering a small amount of money is perceived as more acceptable and pleasant than small gifts except for students from SJK>SMJK. They perceived that small gifts illicit a more pleasant experience. Apart from that, offering small gifts is more acceptable than large money and it was a more pleasant experience. An exception was with students from SJK>SMP who believe the opposite. Students from all types of schools think that bribing because of a delay (deserved giver) is more acceptable than illicit givers. Most of these results are consistent with the survey carried out in Nepal (Truex, 2010). This result could also be explained by using the theory of selfconcept maintenance (Mazar et al., 2008). Respondents indicated that "Due to a delay", bribery is more acceptable. This is the process of rationalisation that might have happened to maintain the self-concept.

There are several limitations in this study. This study is based on a small sample size. Respondents were categorized into four different types of schools without equal numbers for each school. However, the sample represents the actual ratio of students attending different types of schools in real situations. It is recommended for future studies to have a bigger sample size if a similar study is planned. Besides that, the majority of the respondents are Malaysian Chinese. Malaysia consists of 3 main races, Malay, Chinese and Indian. Thus, the result of this study is unable to generalize to the Malaysian population. Nevertheless, the scales used in this self-reported survey yielded high reliability scores. The reader should also bear in mind that overall, there are no significant differences found between schools in attitudes and experiential attitudes. This study reports the descriptive statistics on the differences between respondents who have gone to four different types of schools and their bribe attitudes. Future studies could explore the possible factors that might explain these differences as discussed. With all of these limitations, the result in this study should not be used for generalising or any causation explanation.

\section{Acknowledgement}

The authors greatly appreciate Dr Eliza Berezina, Dr Wu Shin Ling and Dr Yong Min Hooi for their insightful comments and feedback on this paper. This research is made possible with the support from the Malaysian Anti-Corruption Agency (MACC) by providing the research team with data and ideas.

\section{References}

Alatas, S. H. (1991). Corruption: Its nature,causes and functions. Avebury.

Ariely, D. (2012). The honest truth about dishonesty: How we lie to everyone---especially ourselves. HarperCollins. 
Becker, G. S. (1968). Crime and punishment: An economic approach. The Journal of Political Economy, 76(2), 169-217.

Benen, S. (2017). Trump's meeting with the Malaysian leader was anything but normal. In MSNBC. Retrieved from https://on.msnbc.com/3/nDGPF

Birkelund, J., \& Cherry, T. L. (2020). Institutional inequality and individual preferences for honesty and generosity. Journal of Economic Behavior \& Organization, 170, 355-361.

Bradbury, R., \& Yuvaraj, A. (2019). Malaysia has lost about RM47 billion to corruption every year since 2013. In BFM. Retrieved from https://bit.ly/2Ezcmgv

Ciccarelli, S. K., \& White, J. N. (2017). Social Psychology. In Psychology (pp. 522-524). Pearson.

Chen, S. X., \& Bond, M. H. (2010). Two languages, two personalities? Examining language effects on the expression of personality in a bilingual context. Personality \& Social Psychology Bulletin, 36(11), 1514-1528.

Conner, M., McEachan, R., Lawton, R., \& Gardner, P. (2017). Applying the reasoned action approach to understanding health protection and health risk behaviors. Social Science \& Medicine, 195, 140-148.

Costa, A., Foucart, A., Arnon, I., Aparici, M., \& Apesteguia, J. (2014). "Piensa" twice: On the foreign language effect in decision making. Cognition, 130(2), 236-254. https://doi.org/10.1016/j.cognition.2013.11.010

Dong, Y., \& Branscum, P. (2019). What motivates individuals to get obesity related direct-toconsumer genetic tests? A reasoned action approach. American Journal of Health Education, 50(6), 356-365.

Fishbein, M., \& Ajzen, I. (2010). Predicting and changing behavior: The reasoned action approach. Psychology Press.

Francesca, G., Shahar, A., \& Dan Ariely. (2009). Contagion and differentiation in unethical behavior: The effect of one bad apple on the barrel. Psychological Science, 20(3), 393398.

Gill, C. H. D., \& Berezina, E. (2021). School performance in three South East Asian countries: Lessons in leadership, decision-making and training. European Journal of Training and Development, 45(2/3), 136-148. https://doi.org/10.1108/EJTD-01-2020-0014

Gill, S. K., Keong, Y. C., Ong, C., Beng, S., \& Yan, H. (2013). Impact of Chinese Vernacular Medium of Instruction on Unity in Multi-Ethnic Malaysia. Pertanika Journal of Social Science and Humanities, 21, 1039-1064.

Gino, F., Ayal, S., \& Ariely, D. (2009). Contagion and differentiation in unethical behavior: The effect of one bad apple on the barrel. Psychological science, 20(3), 393-398.

Grudgings, S. (2012). Cows and condos scandal highlights Malaysia's faded reforms. In REUTERS. Retrieved from https://www.reuters.com/article/us-malaysia-politics/cowsand-condos-scandal-highlights-malaysias-faded-reforms-idUSTRE81E04020120215

Haney, C., Banks, W. C., Zimbardo, P. G. (1996). The prison simulation. In: Introducing Psychological Research. Palgrave, London. https://doi.org/10.1007/978-1-349-244836_7

Hashim, N. (2017). Development efforts and public sector corruption in Malaysia: Issues and challenges. Journal of Sustainability Science and Management, 12(2), 253-261.

Head, K. J., \& lannarino, N. T. (2017). Understanding the psychosocial influences on high school football players' weight-gaining behaviors. Western Journal of Communication, 81(1), 127-147.

Ivaz, L., Costa, A., \& Duñabeitia, J. A. (2016). The emotional impact of being myself: Emotions and foreign-language processing. Journal of Experimental Psychology, 42(3), 489-496. 
Kapeli, N. S., \& Mohamed, N. (2019). Battling corruption in Malaysia: What can be learned?. Journal of Financial Crime, 26(2), 549-555.

Keysar, B., Hayakawa, S. L., \& An, S. G. (2012). The foreign-language effect: Thinking in a foreign tongue reduces decision biases. Psychological Science, 23(6), 661-668.

Kowalski, R. M. (2007). Bennington college study. The encyclopedia of social psychology. London, United Kingdom: Sage.

Leib, M., Moran, S., \& Shalvi, S. (2019). Dishonest helping and harming after (un)fair treatment. Judgment and Decision Making, 14(4), 423-439.

Lim, I. (2017). What you should know about Chinese schools in Malaysia. In Malay Mail. Retrieved from https://bit.ly/3gtbWpm

Lim, I. (2018). Chinese vernacular students down 110,000 since 2008. In Malay Mail . Retrieved from https://bit.ly/3jf1PGd

Liu, Z., Liu, X., Hong, Y., Brockner, J., Tam, K., \& Li, Y. (2017). Is individual bribery or organizational bribery more intolerable in China (versus in the United States)? Advancing theory on the perception of corrupt acts. Organizational Behavior and Human Decision Processes, 143, 111-128.

Malaysian Government. (1996). Laws of Malaysia: Act 550 : Education Act 1996. Percetakan Nasional Malaysia.

Malaysiakini. What did Mahathir say about the UEC? (2019). In Malaysiakini. Retrieved from https://www.malaysiakini.com/news/458639

Mazar, N., Amir, O., \& Ariely, D. (2008). The dishonesty of honest people: A theory of selfconcept maintenance. Journal of Marketing Research, XLV, 633-644. Retrieved from https://bit.ly/2QE81vv

Ministry of Finance. (2019). Budget 2020. In Ministry of Finance Malaysia official website. Retrieved from https://www.mof.gov.my/arkib/budget/2020/bs20.pdf

Newcomb, T. M. (1943). Personality and social change; attitude formation in a student community. Dryden Press.

Nicholas, P., \& Robertson, D. (2017). Thinking about Bribery neuroscience, moral cognition and the psychology of bribery. Cambridge University Press. Retrieved from https://bit.ly/31uT2Kv

Prenger, R., \& Schildkamp, K. (2018). Data-based decision making for teacher and student learning: A psychological perspective on the role of the teacher. Educational Psychology (Dorchester-on-Thames), 38(6), 734-752.

Rawwas, M., Al-Khatib, J. A., \& Vitell, S. J. (2004). Academic dishonesty: A cross-cultural comparison of U.S. and Chinese marketing students. Journal of Marketing Education, 26(1), 89-100.

Reynolds-Tylus, T., Lukacena, K. M., \& Quick, B. L. (2019). An application of the theory of normative social behavior to bystander intervention for sexual assault. Journal of American College Health, 67(6), 551-559.

Sin Chew Daily. (2008). Huang Baojun: It was known before TNB want to cut electricity. Why does MCA want reporters to witness it? Huang Baojun: It was known before Guoneng cut electricity. Why does MCA want reporters to witness?

https://www.sinchew.com.my/content/content_726250.html

Sipalan, J. (2017). Jeff Sessions calls Malaysia's 1MDB scandal 'kleptocracy at its worst'. In REUTERS. Retrieved from https://www.reuters.com/article/us-malaysia-scandaldoj/jeff-sessions-calls-malaysias-1mdb-scandal-kleptocracy-at-its-worstidUSKBN1DZOMX 
Tian, Q. (2008). Perception of business bribery in China: the impact of moral philosophy. Journal of Business Ethics, 80(3), 437-445. https://doi.org/10.1007/s10551-007-9429-x

Top universities accept the UEC. (2015). In The Star Online. Retrieved from https://www.thestar.com.my/news/nation/2015/11/15/top-universities-accept-theuec/

Truex, R. (2010). Corruption, attitudes, and education: Survey evidence from Nepal. World Development, 39(7), 1133-1142. https://doi.org/10.1016/j.worlddev.2010.11.003

Van Wasshenova, E., Boardley, D., Geers, A., Steiner, V., \& Tull, M. (2018). Experiential attitudes about physical activity in older adults. Retrieved from https://etd.ohiolink.edu/!etd.send_file?accession=toledo1525445315290475\&disposi tion=inline

Wan, C. M., Shen, G. Q., \& Choi, S. L. (2017). Experiential and instrumental attitudes: Interaction effect of attitude and subjective norm on recycling intention. Journal of Environmental Psychology, 50, 69-79. https://doi.org/10.1016/j.jenvp.2017.02.006

White, K. M., Jimmieson, N. L., Obst, P. L., Graves, N., Barnett, A., Cockshaw, W., Gee, P., Haneman, L., Page, K., Campbell, M., Martin, E., \& Paterson, D. (2015). Using a theory of planned behaviour framework to explore hand hygiene beliefs at the ' 5 critical moments' among Australian hospital-based nurses. BMC Health Services Research, 15(59). https://doi.org/10.1186/s12913-015-0718-2

Yusoff, A. (2017). Study: 1 in 3 university students blind to corruption. In FMT. Retrieved from https://bit.ly/3jfOJZI

Zaloznaya, M. (2014). The Social Psychology of corruption: Why it does not exist and why it should. Sociology Compass, 8(2), 187-202. Retrieved from https://doi.org/10.1111/soc4.12120

Zhou, H., Romero, S. B., \& Qin, X. (2016). An extension of the theory of planned behavior to predict pedestrians' violating crossing behavior using structural equation modeling. Accident Analysis and Prevention, 95, 417-424. 